\title{
An Action Research Pilot Study on the Integration of Indigenous Technology in Technology Education
}

\author{
Mishack T Gumbo \\ University of South Africa \\ gumbomt@unisa.ac.za
}

Doi:10.5901/mjss.2014.v5n10p386

\begin{abstract}
My intention with this article is to report how I piloted my action research study on the integration of Indigenous Technology in Technology teaching and learning. This article does not present the findings of the study. Its focus is on the pilot project with the intention to cast light on the importance and function of a pilot study as a forerunner of the main study. Thus, this article accounts for the decisions that I made, implemented and revised based on the realities that I was faced with during the pilot project.
\end{abstract}

Keywords: Pilot study, action research, integration, Indigenous Technology, Technology Education

\section{Background}

\subsection{A pilot study}

There is value to the pilot research that the researcher is planning to conduct. While this may sound pompous, it can also be stated that pilot studies are mostly ignored by researchers because they receive little attention in the scholarly fraternity. L. Thabane, Ma, Chu, Cheng, Ismaila, Rios, Robson, M. Thabane, Giangregorio and Goldsmith (2010, p. 2) claim in this instance that "despite their noted importance, the reality is that pilot studies receive little or no attention in scientific research training". Another claim by Nunes, Martins, Zhou, Alajamy and Al-Mamari (2010), Sampson (2004) and Whithely and Whithely (2005) states that pilot studies are under-reported, specifically in qualitative research literature. This is an undesired situation, especially when considering the fact that pilot studies are instrumental in the framing of questions, collection of background information, refinement of a research approach or tailoring efficient research instruments (Nunes et al., 2010).

The value of pilot studies is premised in their pragmatism as they offer adaptation to the situation on the ground. They could really minimise problems associated with cold, unreflecting emmersion in the field - "immersion in the field without pre-exposure can provide a researcher with a feast of fascinating information and observations and can result in not knowing where to start" (Sampson in Nunes et al., 2010, p. 75). Ashanti's expression emphasises this value of a pilot study: "You never test the depth of a river with both feet" (L. Thabane et al., 2010). It motivates why researchers should seriously consider pilot testing their research studies. De Vaus (1993, p. 54) cautions in this regard: "Do not take the risk. Pilot test first." It is far better to be sure right at the outset whether the study to embark on is worth spending time, resources and energy on before discovering later that all this was a waste (Kraemer, Mintz, Noda, Tinklenberg \& Yesavage, 2006, p. 484; Reiss, n.d.).

This value of the pilot study informed the attitude that I carried into the study implied in this article. I wanted to avoid embarrassing myself to realise only when I was at the point of gathering data that the research participants have crucial questions to ask about my research instrument(s), when this could have been prevented through pilot testing. There could as well be administrative, resource, managerial and scientific reasons for a pilot study (Van Teijlingen \& Hundley, 2002).

But what is a pilot study? A pilot study precedes the main study. It should be planned and conducted; it accounts for what a researcher has learned during its process; it enables a researcher to make the necessary modifications in the main study. A pilot study is pilot testing. It is experimental, exploratory, test, preliminary, trial, try out (Foster, 2013; Van Teijlingen \& Hundley, 2002). A pilot study can be used in qualitative, quantitative or mixed methods studies. A qualitative pilot study, for instance, can be used to develop questionnaire items, then pilot the questionnaire, even the research process (Van Teijlingen \& Hundley, 2002, p. 33). Van Teijlingen and Hundley (2002, p. 33) further define a pilot study as follows: 
Pilot study is a small investigation to test the feasibility of procedures and to gather information prior to a larger study. It is designed to test whether the study is worth pursuing and what changes need to be made. A pilot study is not a feasibility or hypothesis-testing study. It pre-tests or tries out the research instruments. The term 'pilot studies' refers to mini versions of a full-scale study (also called 'feasibility' studies), as well as the specific pre-testing of a particular research instrument such as a questionnaire or interview schedule.

\subsection{Indigenous Technology and Technology teaching and learning}

Indigenous Knowledge Systems (IKSs) and a need to protect the rights of indigenous people are currently enjoying recognition for inclusion in the school curriculum. One of the principles underlying the new curriculum in South Africa, Curriculum and Assessment Policy Statement, is the principle of IKSs. This principle has been maintained from the previous version, National Curriculum Statement. However, Indigenous Technology is less evident in the South African classrooms when it comes to teaching and learning. A study conducted by Gumbo and Williams (2012) in a few selected high schools found Indigenous Technology almost non-existent in the teaching of Technology.

Let me explain Indigenous Technology through IKSs in order to facilitate further meaningful discussion. IKSs in the South African context refer to the body of knowledge embedded in African philosophical thinking and social practices that evolved over thousands of years but were denied full recognition in the school curriculum (Emeagwali, 2003). Bitzer and Menkveld (2004) define IKSs as the combination of knowledge systems encompassing technology, philosophy, social, economic, learning/educational, legal and government systems.

At the centre of IKSs lies indigenous knowledge. Indigenous knowledge reflects the dynamic way in which individuals living in a given locality have come to understand themselves in relation to their natural environment. They organise their folk knowledge of flora and fauna, cultural beliefs, and history to enhance their lives. Dei (2000) asserts that indigenous knowledges refer to the epistemic saliency that is of a cultural nature.

The application of indigenous knowledge to manipulate the environment and find solutions to problems or meet needs comes in the form of Indigenous Technology. Technology essentially drives economic activities and facilitates human interaction. That is why Technology is one of the so-called gateway subjects in school. However, it is important to realise that a learner's learning can be better facilitated when what he is learning relates well to his cultural background and philosophy of life. It follows that Indigenous Technology should be part and parcel of the subject content for the learners, and, most importantly, be taught. The infusion of Indigenous Technology in the curriculum has the potential to make teaching and learning relevant for learners, especially indigenous learners.

In the mainstream educational thinking, many teachers feel that they are losing control if learners do not fit in with their traditional teaching content and teaching methodology (Van Wyk, 2002). According to Van Wyk (2002), IKSs hold valuable implications for teachers in the subject of Technology. The utilisation of Indigenous Technology and African IKSs is the key to unlocking the door that has prevented the masses from accessing mathematics, science and engineering (Seepe, 2004). The artifacts that indigenous people produce as their rules and routines are the manifestation of their explicit knowledge (Ngubane, 2003). These are evident in the following technological areas: food technology (Okagbue, in Emeagwali, 2003); metallurgical technology (African Technology Policy Studies Network, 2010; Emeagwali, 2003; Van Sertima, 1991); astronomical technology (Adams III, 1983; Van Sertima, 1991; Tedla, 1995); tools technology (Technology Policy Studies Network, 2010); architecture and engineering technology (Emeagwali, 2003; M. Asante \& K. Asante, 1983; Maluleka, Wilkinson \& Gumbo, 2006; Tedla, 1995); transport technology (Van Sertima, 1991); agricultural technology (Dakora, 1996; Hardin, 1996; Rowlands \& Warnier, 1996); medical technology (Jonathan, 1996; Emeagwali, 2003); and communication technology (Tedla, 1995). Feenberg (2006) writes about the value-laden nature of technology - it is never context-free or neutral.

Banhardt and Kawagley (2005) assert that the cultural histories and practices of native learners are rarely incorporated in the learning environment. Banhardt and Kawagley (2005) cite Battiste, who in concurrence with Michie (1999), holds that learners in indigenous societies around the world have demonstrated a distinct lack of enthusiasm for the experience of schooling in its conventional form, an aversion that is most often attributable to an alien institutional culture. The curricula, teaching methodologies and assessment strategies associated with mainstream schooling are based on a worldview that does not adequately recognise or appreciate indigenous notions of an interdependent universe and the importance of place in their societies (Kawagley, Norris-Tull \& Norris-Tull, 1998). Hence, research into the integration of Indigenous Technology was deemed important in the study that was piloted. The research question that was addressed in the study was: How can Technology teachers be helped to integrate Indigenous Technology in their teaching to facilitate meaningful learning in learners? 


\section{Research Design for the Pilot Study}

I applied to the Department of Education and obtained permission to access the research site. According to Stringer (1999), permission for access to the context must be sought from people in positions of influence and authority for legal recognition and support. The research was piloted in the Mabopane district of the North-West Province. The choice of this district was informed by practical reasons - distance, time and cost. I took a copy of the permission letter with to negotiate access into the school. The school that was chosen for this pilot is located in the semi-rural Winterveldt, North of Pretoria.

I selected all five Technology teachers (four males and one female) who taught Grade 7, 8 and 9, and ten Grade 7 Technology learners (five boys and five girls) who were targeted for interviews and implementation of the lesson that integrated Indigenous Technology. However, the fifth teacher, who was a Head of Department, could not participate due to his very busy schedule. The four teachers were assigned the following pseudonyms, $t A, t B, t C$ and $t D$ ( $t$ for teacher), for confidentiality purposes. Grade 8 and 9 Technology learners were not involved as I wanted to limit the numbers in order to manage the action research activities well.

Data collection was done by following Kurt Lewin's model of action research (Elliot, 1991, p. 70) depicted in figure 1. Data collection methods are also included.

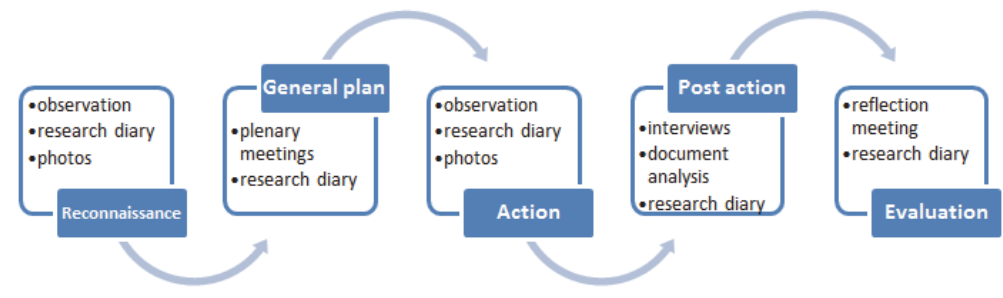

Figure 1: Data gathering and methods

During fact-finding (reconnaissance) I spent a day at the school to observe. This was an entry observation during which I interacted with the principal and teachers to get their views about Technology Education as a relative newcomer to the curriculum, observed teachers teaching the subject and talked to them. I was on the lookout for any indications of Indigenous Technology being integrated in their teaching and displayed somewhere in the classrooms. I took pictures to inform my observation in addition to the research diary. Photographs count as documents, artifacts and evidence of human behaviour in naturalistic settings and thus supplement other data collection techniques. They function as windows (McKernan, 1991) into the context where research is taking place.

Then I held four general plenary meetings with the teachers which took place over a few days. During these meetings we planned a lesson that integrated Indigenous Technology. As part of planning during the fourth meeting, the teachers asked the learners to bring from home any small artifact that represented forms of structure in their indigenous contexts. I noted major points from the meetings in my research diary. The first meeting was about clarifying the purpose of the research and negotiating meaning of Indigenous Technology so that lesson planning could be done with a good understanding of the concept and to encourage participation (Stringer, 1999).

The plenary meetings led to giving the lesson in the class. The lesson was based on the theme of structures in accordance with the teachers' plan for the year. This particular lesson integrated indigenous structures. The lesson was implemented during the Technology Education double period that lasted 60 minutes. Two Technology Education classes were combined in a bigger classroom. One teacher facilitated the lesson while her colleague who was free and I observed. I asked him to write down his observations and give them to me at the end of the lesson. I used my research diary to note mine, too. I also took pictures during the lesson. The facilitator organised the learners into groups, introduced the lesson, and assigned the learning activities.

Immediately after the lesson I interviewed the two teachers that I involved in the lesson, to gather their views on the integration of Indigenous Technology. The opening question for the facilitator was, "What can you share about the lesson you have just conducted?" For the observer, the opening question was, "Please share with me your experiences about the lesson you and I have just observed." Thereafter I interviewed the ten selected learners. The opening question for the learners was: "Share with me what you have learned from today's lesson of Technology." The interviews were recorded.

Then I had a reflection (evaluation) meeting with the teachers. It was mainly about evaluating the implemented 
lesson, but also about how the action research activities went. I asked the teachers a question: "What have we learned from our project?" I allowed the teachers the opportunity to share their views. Since this was a pilot study, the action research activities were closed at this point.

In order to submit an informed review of the pilot study, I analysed the data. I used coding and triangulation for this purpose. Triangulation is a procedure for organising different types of evidence into a more coherent frame of reference or relationship so that they can be compared and contrasted (McKernan, 1991). Simple and confirmatory triangulation emanates from the agreeing of every kind of evidence. Coding is the translation of question responses and respondent information to specific categories for the purpose of analysis (Cohen \& Manion, 1989). The following three coding procedures were considered (Neumann, 2000, p. 421):

- open coding, which is about the identification of themes and the initial labeling of data;

- axial coding, which is about organising emergent ideas and/or themes as well as reflecting on the causes and consequences, conditions and interactions, strategies and processes suggested in the data; and

- selective coding, which is about scanning classified data with a view to identify similarities and/or differences in and among the identified categories.

I also sourced McMillan's and Schumacher's (2001) data organisational strategy. Data were thus organised into three stages of analysis. Data analysis shows three stages that I applied. The first stage is the analysis of data according to its separate data types and sub-data types, for instance interviews for teachers and learners; combined sub-types or segments of data within individual data types and a comparative analysis, for instance established themes across teachers' and learners' interviews; and a synthesis of all data types.

I also had to think about issues of validity during the pilot. According to McMillan and Schumacher (2001, p. 407), validity addresses the questions: "Do researchers actually observe what they think they observe?" and "Do researchers actually hear the meanings that they think they hear?" I considered the following aspects to ensure validity, according to the model of McNiff (1988, p. 39):

- Self-validation to justify a claim to knowledge is achieved through practice as a realisation of values. An educational enquiry begins with a declaration, spoken, written or thought of values. Often the enquiry comes into being because those values are being denied in practice. This is where the cycle of imagined solutions, implementation, observation, evaluation and re-planning is enacted. The desire to turn a negative state into a positive one, the motivation to improve education, acts as an incentive for the enquiry. I enacted this step through this action research on the integration of indigenous technologies in the Technology Education curriculum and teaching. This investigation was inspired by my realisation that Indigenous Technology was being downplayed to some extent due to its historical marginalisation.

- Intentional critical reflection is the way in which a naïve understanding of practice is transformed; where the practitioner reflects upon instead of merely experiencing practice; and where the process is made public and shared so that others gain an understanding of the practice. A claim to be able to explain one's own educational development depends on critical reflection, a desire to explore an intuitive understanding of practice and communicate it to others. This action research started with an inquiry into the question of the marginalisation of Indigenous Technology and a need to create an understanding thereof for possible integration in the Technology Education curriculum and teaching. And my ultimate aim was to disseminate this transformational study via discussion with the teachers that were involved in the study, and by publishing the results. Thus, this paper is one of those ways of disseminating the results. However, this paper is confined to reporting on how the pilot study helped me to review my data gathering methods and processes. It does not report the findings of the study per se.

- A need for disciplined enquiry through a series of questions offers a common-sense procedure for pinpointing crucial stages in an enquiry. This pivots upon an action-reflection cycle into a pattern of statements to make action research meaningful: 1) I experience a problem when some of my educational values are denied in practice; 2) I imagine a solution to the problem; 3) I implement the imagined solution; 4) I evaluate the outcome of my actions; 5) I re-formulate my problem in the light of my evaluation. These questions relate to the action research mode, which is the attitude that I adopted embarking on this study.

- Personal interpretations as a basis for dialogue should come to the fore in academic engagements. The most underrated quality of teachers is their intuitive, tacit knowledge. The purpose with the action-reflection cycle is to strip away the mutilations which centuries of objectivist thought have imposed on the minds of men. This study offers one way of stripping away these mutilations.

- Peer validation offers a platform for the research findings to share a social value as they are communicated to 
others. This implies engaging one's intuitive knowledge publicly in debate to gain external validation by others who may also agree that the findings will be useful to their own practice. It is therefore necessary to hold validation meetings at critical intervals in the research study. The plenary and reflection meetings with the actively involved participants helped take care of this matter.

- Learner validation is particularly useful in order to get on record the reactions of the clients (teachers and learners in this case) themselves. Their evidence is perhaps the strongest support in the researcher's claim to knowledge. This may be presented in short written statements, diaries, or tape or video recordings. The multimethod approach that I applied helped with the gathering of evidence from the client's point of view.

Validity in this study was premised on a combination of any of these possible strategies (McMillan \& Schumacher, 2001): prolonged and persistent fieldwork; multi-method strategies; participants' verbatim accounts; multiple researchers (research team); mechanically recorded data; participant researcher; member checking; participant review.

So, which modifications with justification were worthy of consideration in the pilot study in order to ensure a tight approach to conducting the main study?

\section{How Did the Pilot Study Help Me Revise My Research Design?}

I found it very important to come up with a more enhanced plan for reconnaissance due to suspicion that I did not cover enough of this stage in the pilot study. I reviewed my observation by specifying what I intended to observe: situation and layout of the schools, school facilities, technological symbols/pictures/artifacts and indications of indigenous technologies, school timetables, school culture, interaction among teachers, interaction among teachers and learners, interaction among learners, teaching and learning activities in Grade 7 classes. I planned to record these observations in my research diary.

Secondly, I shifted the teachers' interviews from after the lesson to the reconnaissance stage so that this could better inform the planning of my meetings with the teachers. I added free-attitude interviews (Meulenberg-Buskens, 1997) in respect of the teachers' interviews to help increase their participation through probing techniques, for instance "What do you mean?" "Tell me more" "Clarify", and the use of silence as an effective technique to get more information from the respondents. I realised the importance of incorporating the biographical information of teachers during plenary meetings.

I maintained the general plan with a few modifications. I reduced my plenary meetings to three by combining the third and fourth meetings about the planning of the lesson. I also expanded the lesson by including more learning activities, that is, four activities instead of one. I developed an observation sheet with items on which teachers can write down their observations during the lesson (see Appendix 1). It would take approximately three days to implement this lesson.

I maintained the after-lesson unstructured interviews with the learners because they went well during the pilot and the learners were very interested and participated enthusiastically. I maintained the evaluation meeting for the main action research study, but incorporated the validation questions for the teachers.

I discarded a document evaluation meeting and replaced it with a document evaluation sheet that I would administer to teachers (see Appendix 2). I wanted them to scrutinise the documents concerned and to respond to the items in the evaluation sheet. I wanted to only facilitate this exercise and trust the teachers' views since they worked with the documents in question and would thus do a good job.

In terms of the needed resources, I was reasonably satisfied that the budgeted resources sufficed and were in good working condition, for instance the recording device.

\section{Conclusion}

This article reported the pilot study for the action research study that I intended to conduct. The importance of a pilot study was emphasised in the article. I also included a section on the concept of Indigenous Technology to provide a brief background about what the study intended to investigate. The crux of the article is found in the methodology: how I implemented the pilot study and reviewed my decisions and plans.

It is highly recommended that a research study is piloted to ensure the appropriateness of research instruments from the participant's perspective, and to tighten the feasibility of the study in terms of time, costs, manageability and resources. 


\section{References}

Adams III, H. H. (1983). African observers of the universe: The Sirius question. In Van Sertima, I. V. (ed.). Blacks in science: Ancient and modern. New Brunswick, NJ: Transaction Books.

African Technology Policy Studies Network. (2010). The African Manifesto for Science, Technology and Innovation. Nairobi: African Technology Policy Studies Network.

Asante, M. \& Asante, K. (1983). Great Zimbabwe: An ancient African city-state. In Van Sertima, I. V. (ed.). Blacks in science: Ancient and modern. New Brunswick, NJ: Transaction Books.

Barnhardt, R. \& Kawagley, A. O. (2005). Indigenous knowledge systems and Alaska native ways of knowing. Anthropology and Education Quarterly, 36(1), 8-23.

Bitzer, E. \& Menkveld, H. (2004). Drawing on indigenous knowledge: Students learning in and from a rural community. South African Journal of Higher Education, 3(18), 226-240.

Cohen, L. \& Manion, L. (1989). Research methods in education (3rd edition. London: Routledge.

Dakora, F. D. (1996). Using indigenous knowledge to increase agricultural productivity in Africa. In Normann, H., Snyman, I. \& Cohen, M. (eds.). Indigenous knowledge and its uses. Pretoria: HSRC.

Dei, G. J. S. (2000). Rethinking the role of indigenous knowledges in the academy. International Journal of Inclusive Education, 4(2), 111-132.

De Vaus, D. A. (1993). Survey in Social Research (3rd edition). London: UCL Press.

Elliot, J. (1991). Action research for educational change. Buckingham: Open University Press.

Emeagwali, G. (2003). African Indigenous Knowledge Systems (AIK): Implications for the curriculum. In Falola, T. (ed.). Ghana in Africa and the world: Essays in honour of Adu Boahen. New Jersey: Africa World Press.

Feenberg, A. (2006). What is philosophy of technology? In Dakers, J. (ed.). Defining technological literacy: Towards an epistemological framework. New York: Palgrave Macmillan.

Foster, R. L. (2013). What a pilot study is and what it is not. Journal for Specialists in Pediatric Nursing, 18, 1-2.

Gumbo, M.T. \& Williams, P.J. (2012). Technology teachers' Pedagogical Content Knowledge: An exploratory study - Monograph. Germany: Lambert.

Hardin, K. L. (1996). Technological style and the making of culture: Three Kono contexts of production. In Arnoldi, M. J., Geary, C. M. \& Hardin, K. L. (eds.). African material culture. Bloomington: Indiana University Press.

Jonathan, L. T. (1996). Traditional versus modern medicine: The case for a collaborative approach to Primary Health Care (PHC). Journal of Research: Ethnomedicine in Southern Africa, 4, 9-18.

Kawagley, A. O., Norris-Tull, D. \& Norris-Tull, R. A. (1998). The Indigenous worldview of Yupiaq culture: Its scientific nature and relevance to the practice and teaching of science. Journal of Research in Science Teaching, 35(2), 133-144.

Kraemer, H. C., Mintz, J., Noda, A., Tinklenberg, J. \& Yesavage, J. A. (2006). Caution regarding the use of pilot studies to guide power calculations for study proposals. Arch Gen Psychiatry, 63, 484-489.

Maluleka, K., Wilkinson, A. \& Gumbo, M. (2006). The relevance of Indigenous Technology in Curriculum 2005/RNCS with special reference to the Technology Learning Area. South African Journal of Education, 26(4), 501-513.

McKernan, J. (1991). Curriculum: Action research - A handbook of methods and resources for the reflective practitioner (2nd edition). London: Kogan Page.

McMillan, J. H. \& Schumacher, S. (2001). Research in education (5 $5^{\text {th }}$ edition). Longman: New York.

McNiff, J. (1988). Action research: Principles and practice. Routledge: New York.

Meulenberg-Buskens, I. (1997). Turtles all the way down? On a quest for quality in qualitative research. South African Journal of Psychology, 27(2), 111-115.

Michie, M. (1999). Where are indigenous peoples and their knowledge in the reforming of learning, curriculum and pedagogy? Paper presented at the Fifth UNESCO-ACEID International Conference "Reforming learning, curriculum and pedagogy: Innovative visions for the new century". Bangkok, Thailand.

Neumann, W.L. (2000). Social research methods: Qualitative and quantitative approaches (4th edition). Boston: Allyn and Bacon.

Ngubane, P. (2003). Using the SECl knowledge management model and other tools to communicate and manage tacit indigenous knowledge. Innovation, 27, 21-30.

Nunes, B. M., Martins, T., Zhou, J., Alajamy, L. M. \& Al-Mamari, S. (2010). Contextual sensitivity in grounded theory: The role of pilot studies. The Electronic Journal of Business Research Methods, 8(2), 73-84.

Reiss, C. R. (n.d.). The importance of pilot studies in the development of large-scale seawater desalination plants. [Online] Available: www.twdb.state.tx.us/publications/reports/numbered_reports/doc/R363/C5.pdf. January 19, 2014.

Rowlands, M. \& Warnier, J. (1996). Magical iron technology in the Cameroon Grassfields. In Arnoldi, M. J., Geary, C. M. \& Hardin, K. L. (eds). African material culture. Bloomington: Indiana University Press.

Sampson, H. (2004). Navigating the waves: The usefulness of a pilot in qualitative research. Qualitative Research, 4, 383-402.

Seepe, S. (2004). Editorial note. South African Journal of Higher Education, 18(3), 9-16.

Stringer, E. T. (1999). Action research (2nd Edition). London: Sage Publications.

Tedla, E. (1995). Sankofa: African thought and education. New York: Peter Lang.

Thabane, L., Ma, J., Chu, R., Cheng, Ji., Ismaila, Rios, A., Robson, L. P., Thabane, M., Giangregorio, L. \& Goldsmith, C. H. (2010). A tutorial on pilot studies: The what, why and how. BMC Medical Research Methodology, 10, 1.

Van Sertima, I. (1991). The lost sciences of Africa: An overview. In Van Sertima, I.(ed.). Blacks in science: Ancient and modern. New Brunswick, $\mathrm{NJ}$ : Transaction Books.

Van Teijlingen, E. \& Hundley, V. (2002). The importance of pilot studies. Nursing Standard, 16(40), 33-36.

Van Wyk, J. (2002). Indigenous knowledge systems: Implications for natural science and Technology teaching and learning. South African Journal of Education, 22(4), 305-312.

Whitheley, A. \& Whitheley, J. (2005). The familiarization study in qualitative research: From theory to practice: Graduate School of Business Working Paper 51. Perth, Australia. 


\section{Appendix 1:}

Observation during the lesson

Observer's name:......

Name of school:

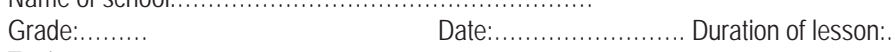

Topic:.

.

Please share your observations during the lesson by responding to the following questions:

1. What learners' background knowledge is articulated in the learning activity?

2. Where, when and how were indigenous technologies referred to during the learning activity?

3. Where, when and how were artefacts relating to indigenous technologies used during the learning activity?

4. Note the level of learners' participation during the learning activity. Why is it this way?

5. Note learners' answers to the teacher's questions.

6. Note any life-world experiences learners make references to; how and when?

7. What more did you notice during the learning activity?

\section{Appendix 2:}

Document evaluation sheet

Evaluator's name:

Grade:

Name of school ...

Type of document evaluated:

Title of document:

Author or source:

Publisher:......

Year of publication:

Please evaluate the documents you are using at the school by responding to the following items:

1. Comment on the content of the document.

2. Comment on the relationship between the content knowledge in the document and the knowledge that learners bring to school.

3. Relate the extent to which the document preserves, develops and promotes the understanding of indigenous knowledge and technological practices.

4. Comment on the extent to which the document accommodates the richness of indigenous cultures with respect to:

a) the technological concepts and language used in the material being evaluated.

b) the relevancy of the document to the grade you teach.

c)

c) outside and the inside layout of the document.

d) pictures and graphs.

e) examples and scenarios drawn. 